\title{
Stone mastic asphalt as an ungrooved runway surface: Case study on Emerald airport
}

\author{
G. White \\ H. Dutney \\ Airport Engineer, GHD Pty Ltd, Brisbane, Queensland, Australia
}

School of Science and Engineering, University of the Sunshine Coast, Sippy Downs, Queensland, Australia

\begin{abstract}
The pavements at Emerald airport, located in central western Queensland, were resurfaced in 2019. The taxiway and apron were surfaced with dense graded asphalt (DGA) and the runway was surfaced with stone mastic asphalt (SMA). The project was a pilot project to demonstrate ungrooved SMA is a viable alternate to grooved DGA for runway surfacing in Australia. The mixture designs indicated that the SMA is expected to perform in the field similarly to the DGA, with regard to fracture, deformation and moisture damage resistance. The construction trial and surface construction confirmed that the surface texture exceeded the regulatory requirements, as did the wetted surface friction values. Furthermore, the aircraft skid resistance compliance was achieved immediately following construction, which is a significant advantage over grooved DGA, which usually does not achieve compliance until the grooves are sawn some 4-8 week later. The production and construction results demonstrated the ability of the continuous drum mixing plant to achieve adequate SMA production consistence, comparable to that expected for DGA. However, it is recommended that the asphalt production binder content acceptance tolerance be increased for SMA, to reflect the more variable nature of the test results due to unavoidable contamination of the tools by the high bituminous binder content associated with SMA. The project also highlighted the need to monitor the SMA construction to minimise the risk of isolated bitumen-rich spots. Overall, the project was successful and it is recommended that other airports consider ungrooved SMA as an alternate to grooved DGA in the future. Ongoing monitoring of the SMA surface at Emerald airport is required to determine the performance with age, compared to otherwise similar DGA in the same environment.
\end{abstract}

Keywords: Stone mastic, Airport, Runway, Ungrooved, Surface

\section{INTRODUCTION}

Emerald airport is located approximately $5 \mathrm{~km}$ south of the town of Emerald in the Central Highlands region of Queensland, Australia. The airport provides medical and general support to the township, which is approximately a 10 -hour drive from the state capital, Brisbane. The airport services approximately eight public transport flights per day, including regional turboprop and jet aircraft.

The main runway at Emerald airport is nominally $30 \mathrm{~m}$ wide and approximately $1,900 \mathrm{~m}$ long, with turning nodes at each end. Two perpendicular taxiways connect the runway to the parking apron, which provides six permanent parking bays (Figure 1). In 2018, the 
runway surface was old and severely eroded (Figure 2) with some isolated depressions near the two runway ends. In 2019 the runway was resurfaced, including isolated patching of depressed pavement areas, unpaved flank regrading, airfield lighting modifications and re-linemarking. One of the taxiways and approximately half of the parking apron were also resurfaced, but the secondary runway and the associated taxiway and apron for light aircraft were not.

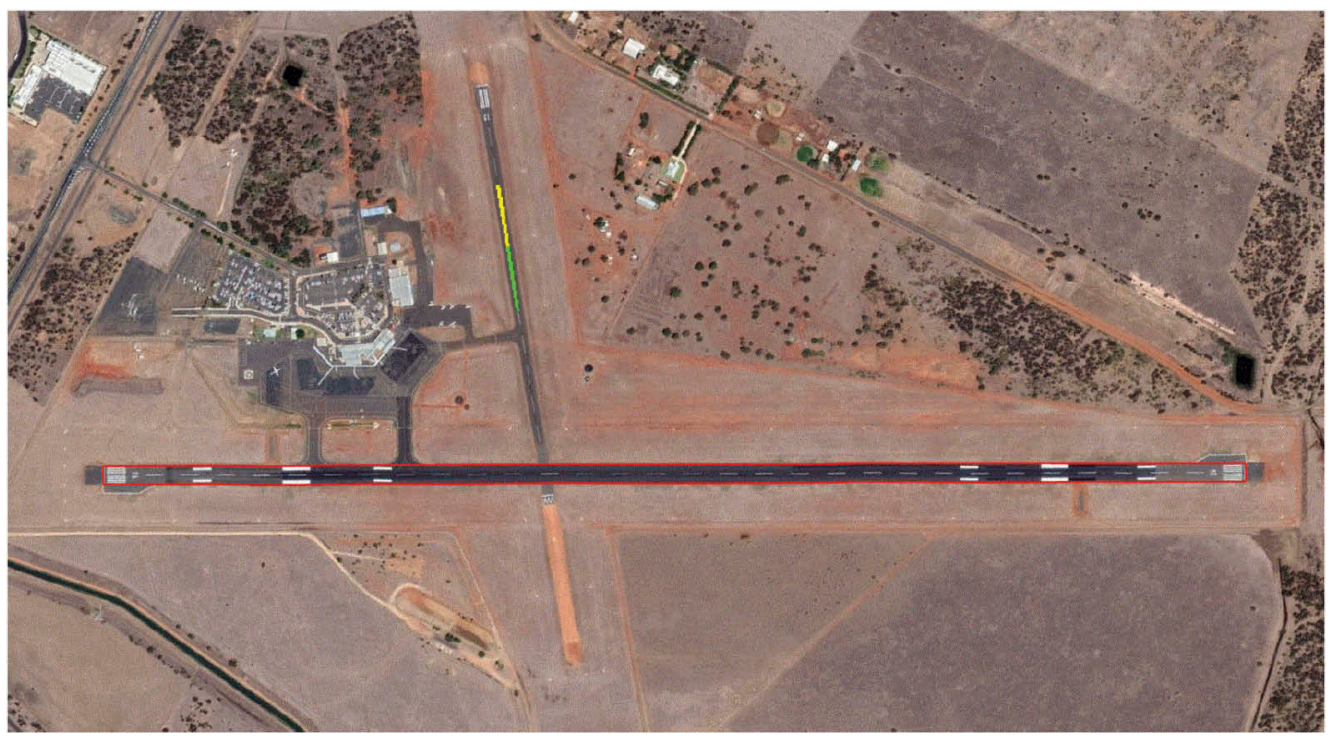

Figure 1. Emerald airport, the area of study outlined in red and the area of construction trial filled in yellow (SMA) and green (DGA).

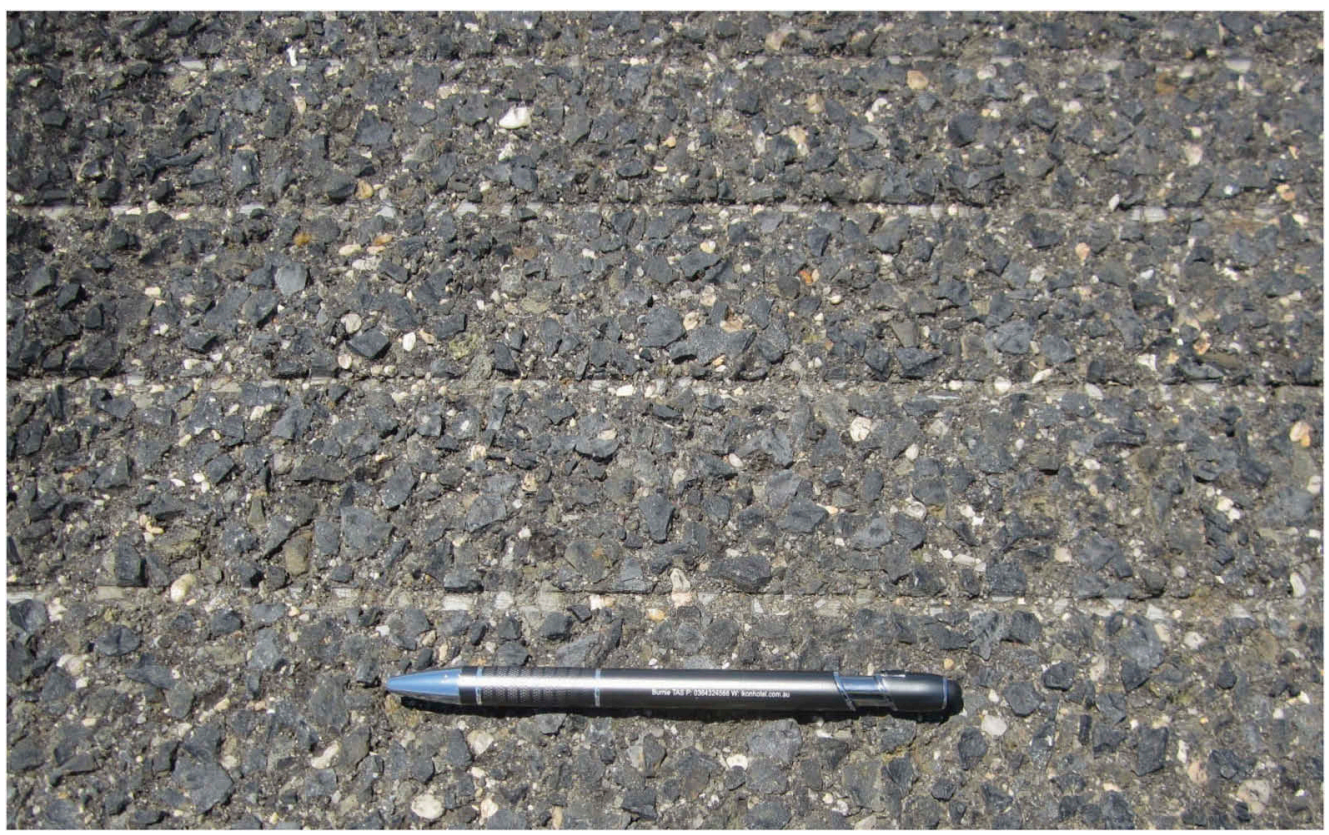

Figure 2. Typical runway surface prior to 2019 resurfacing. 
The resurfacing work was originally planned to use the grooved dense graded asphalt (DGA), which has been normal in Australia since the 1990s, designed, produced and constructed according to the Australian performance-related airport asphalt specification (AAPA 2018). However, recent Australian research on the introduction of stone mastic asphalt (SMA) as an ungrooved runway surface (Jamieson 2019) prompted the runway to be surfaced with ungrooved SMA, as a pilot or demonstration project. Factors that made Emerald airport well suitable to being a pilot SMA runway surfacing included:

- local availability of aggregate sources that met the slightly stricter requirements of airport SMA, compared to aggregate requirements for use in airport DGA,

- relatively good access windows in which to perform the resurfacing works, compared to busier major city airports,

- the semi-arid environment which means that the runway at Emerald airport would only be grooved to meet the regulatory requirements for aircraft skid resistance, rather than an actual underlying desire for a grooved runway surface.

Initially, only the rectangular $30 \mathrm{~m}$ by $1,900 \mathrm{~m}$ of the runway was intended to be surfaced with SMA. The turning node widenings at each runway end, the taxiway and aircraft parking apron were all intended to be surfaced with ungrooved DGA because aircraft skid resistance requirements do not apply to these areas. Furthermore, underlying patching and shape correction was intended to be performed using DGA. However, as detailed later, a range of issues resulted in more of the work being completed with SMA than originally intended. However, this case study is focussed primarily on the $30 \mathrm{~m}$ by $1,900 \mathrm{~m}$ rectangular portion of the runway surfaced with generally 40-60 mm of SMA over a variable thickness of shape correcting DGA.

Being the first significant runway in Australia to be resurfaced with ungrooved SMA, there was considerable uncertainty regarding the outcomes. Practitioners and airport managers questioned whether the SMA would:

- be porous, allowing water to enter the surface layer,

- perform as well as dense graded asphalt,

- have a comparable lifespan to otherwise similar DGA,

- achieve the surface texture and wetted friction levels required by regulations,

- be able to be produced reliably in typically available mobile drum production plants, and

- cost significantly more than grooved DGA.

This paper presents the resurfacing of Emerald airport's runway as a case study on the use of SMA as an ungrooved runway surface. The aim is to answer the various questions raised by practitioners regarding the viability of SMA as an ungrooved runway surface, in order to enable SMA to be considered for other regional airport runway resurfacing works in Australia. The mixture design is compared to the specification requirements and the construction planning is outlined, along with the execution and monitoring of the construction trial. The asphalt production and surface construction quality assurance testing results are then compared to the specification requirements, before the surface texture and wetted friction results are presented and compared to regulatory aircraft skid resistance requirements. Finally, the cost of the SMA resurfacing is compared to the cost of the grooved DGA alternate.

\section{BACKGROUND}

\subsection{Airport asphalt surface performance}

In 2017, Australia developed performance requirements for DGA used as an airport pavement surface (Table 1). A performance-related specification was subsequently developed (AAPA 2018). The specification retains the traditional DGA mixture volumetrics and composition, but allows the mixture designer to select or develop any bituminous binder to achieve the specified asphalt performance properties (Table 2). This approach reflects the absence of a reliable durability test, meaning that the traditional volumetric composition continued to be 
the primary basis on which reasonable weather-related durability is controlled. However, deformation resistance, fracture resistance and moisture-related durability are now controlled by performance-related laboratory testing at the mixture design stage. Surface friction and testing are more complex and these are discussed further below.

Table 1. Summary of airport asphalt performance requirements (White 2018).

\begin{tabular}{lll}
\hline Physical requirement & Protects against & Level of importance \\
\hline Deformation resistance & $\begin{array}{l}\text { Groove closure } \\
\text { Rutting } \\
\text { Shearing/shoving } \\
\text { Top down cracking }\end{array}$ & High \\
Fracture resistance & $\begin{array}{l}\text { Fatigue cracking } \\
\text { Skid resistance } \\
\text { Compliance requirement } \\
\text { Surface friction and texture }\end{array}$ & Moderate \\
Durability & Resistance to moisture damage & High \\
& Moderate \\
\hline
\end{tabular}

Table 2. Performance-related airport asphalt requirements (AAPA 2018).

\begin{tabular}{lll}
\hline Test Property & Test Method & Requirement \\
\hline $\begin{array}{l}\text { Indirect Tensile Strength Ratio } \\
\text { (TSR) }\end{array}$ & AG:PT/T232 & Not less than $80 \%$ \\
$\begin{array}{l}\text { Wheel Tracking Test }(10,000 \text { passes } \\
\left.\text { at } 60^{\circ} \mathrm{C}\right)\end{array}$ & AG:PT/T231 & Not more than $2.0 \mathrm{~mm}$ \\
Fatigue life (at $20^{\circ} \mathrm{C}$ and $\left.200 \mu \mathrm{m}\right)$ & $\mathrm{AG}: \mathrm{PT} / \mathrm{T} 274$ & $\begin{array}{l}\text { Not less than } 500,000 \text { cycles to } 50 \% \text { of initial flex- } \\
\text { ural stiffness }\end{array}$ \\
\hline & &
\end{tabular}

In 2019 the Australian performance-related specification for dense graded airport asphalt was expanded to include the requirements of SMA (Jamieson \& White 2019). The incorporation of SMA into the specification required:

- minor changes to aggregate property requirements for reliable SMA production,

- adding SMA volumetric composition requirements for mixture design,

- adding volumetric surface texture and binder drain down tests to SMA mixture design, and

- adding the testing and reporting of surface texture during construction.

Despite these changes, the performance requirements (Table 2), asphalt production tolerances and surface construction processes, field air voids content limits and general quality requirements were kept the same for SMA as they were for DGA. A draft of the updated specification was used for the resurfacing of the runway at Emerald airport, with minor changes to the specification made as a result of the lessons learnt from the project.

\subsection{Aircraft skid resistance}

The physical requirements of runways are specified by the International Civil Aviation Organization (ICAO) through a document commonly known as Annex 14 (ICAO 2013). In Australia, these requirements are implemented by the Civil Aviation Safety Authority (CASA) through their Manual of Standards Part 139 (MOS 139) (CASA 2019). Regarding aircraft skid resistance, MOS 139 requires all runways to be constructed and maintained throughout their lifecycle to provide either: 
- surface macro-texture exceeding $1 \mathrm{~mm}$, or

- friction levels that exceed the minimums recommended by ICAO, or

- sawn grooves perpendicular to the runway centreline.

Surface macro-texture is commonly measured by volumetric sand patch or estimated by a laser scanner (White et al. 2019). Friction levels must be measured by continuous friction measuring equipment (CFME) immediately behind the application of a nominal $1 \mathrm{~mm}$ film of water (FAA 1997). Grooves are traditionally $6 \mathrm{~mm}$ deep and $6 \mathrm{~mm}$ wide, spaced $38 \mathrm{~mm}$ from centre to centre, but trapezoidal grooves of equivalent volumetric density (Zuzelo 2014) are becoming popular in some countries, including Australia.

Grooved DGA relies on the presence of grooves to achieve adequate aircraft skid resistance. In contrast, SMA relies on surface macro-texture for regulatory compliance. Either way, CFME survey results are commonly used to verify wet friction levels and to assist in the management of friction over the lifetime of an asphalt surface (White \& Azevedo 2022). Because it is not grooved, SMA must reliably provide a surface macro-texture not less than $1.0 \mathrm{~mm}$, and/ or return wetted friction levels that exceed the maintenance interventions levels recommended by ICAO.

The performance-related airport asphalt specification (AAPA 2018) did not have friction or surface texture requirements for DGA, except to test and report the wetted friction on completion of the resurfacing work. This reflects the inability of an asphalt mixture designer to significantly control the friction, the inability to test wetted friction at high speeds until at least $500 \mathrm{~m}$ of the surface is constructed, and the general reliance on post-construction grooving to meet the regulatory requirement for friction. When SMA is used, the primary means of achieving regulatory compliance is surface macro-texture. Therefore, volumetric surface texture was added to the mixture design requirements, as well as to the construction trial process. Surface texture was also added to the construction quality control testing, as a report only parameter, in addition to the wetted friction levels on completion of the construction.

\subsection{Dense graded versus stone mastic asphalt}

As stated above, airport asphalt in Australia and many other countries is predominantly DGA designed according to the Marshall method (White 1985) with samples compacted by 75 blows of a Marshall hammer. Runway asphalt generally has a $14 \mathrm{~mm}$ maximum nominal aggregate size. In contrast, SMA is designed using 50 blows of a Marshall hammer, to prevent aggregate particle crushing, has a gap graded coarse aggregate skeleton, a higher bituminous binder content and a higher fine aggregate content. The coarse aggregate skeleton provides stone-on-stone contact to provide high deformation resistance, while the high mastic (combination of binder and fine aggregate) content fills the additional voids in the coarse aggregate skeleton and produces a non-porous mixture that has high resistance to fracture and ageing because of the high bituminous binder content. Table 3 and Figure 3 detail the volumetric properties specified in the preliminary airport DGA/SMA specification. The laboratory asphalt mixture performance requirements are the same for both SMA and DGA, as detailed in Table 2.

In practice, Marshall designed airport DGA usually contains $0.5-1.5 \%$ hydrated lime as an active filler. The higher fine content associated with SMA would require more than $4 \%$ hydrated lime, which would excessively stiffen the mixture. Therefore, a blend of hydrated lime and crushed limestone is usually used for SMA production. Furthermore, the wider SMA envelope associated with the $4.75-9.5 \mathrm{~mm}$ sieves is required because SMA is generally produced from fewer aggregate fractions, resulting in less control of the overall grading, as well as the comparatively lower portions retained on the larger sieves, meaning that changes in the $14 \mathrm{~mm}$ and $10 \mathrm{~mm}$ aggregate fraction gradings has a greater impact on the overall grading on these sieves. 
Table 3. Volumetric properties of SMA and DGA.

\begin{tabular}{lllll}
\hline Property & Units & Test method & Dense graded & Stone mastic \\
\hline Maximum size & $\mathrm{mm}$ & N/A & 14 & 14 \\
VMA & $\%$ (by volume) & AS/NZS 2891.8 & $13-17$ & $17-20$ \\
VFB* & $\%$ (by volume) & AS/NZS 2891.8 & $70-80$ & $75-85$ \\
Air voids & $\%$ (by volume) & AS/NZS 2891.8 & $3.5-4.5$ & $3.0-4.0$ \\
Binder content* & $\%$ (by mass) & AS/NZS 2891.8 & $5.2-5.8$ & $6.2-6.8$ \\
Binder type & N/A & Selected by designer & Polymer modified & Polymer modified \\
Surface texture & $\mathrm{mm}$ & Sand patch & Not applicable & $>1.0$ \\
Binder drain down & $\%$ & AG:PT/T235 & Not applicable & $<0.3$ \\
Layer thickness & $\mathrm{mm}$ & For construction planning & $40-80$ & $45-60$ \\
\hline
\end{tabular}

$\mathrm{VMA}=$ voids in the mineral aggregate, VFB is the voids filled with binder. ${ }^{*}$ denotes properties not explicitly specified but are effectively fixed by other specification requirements.

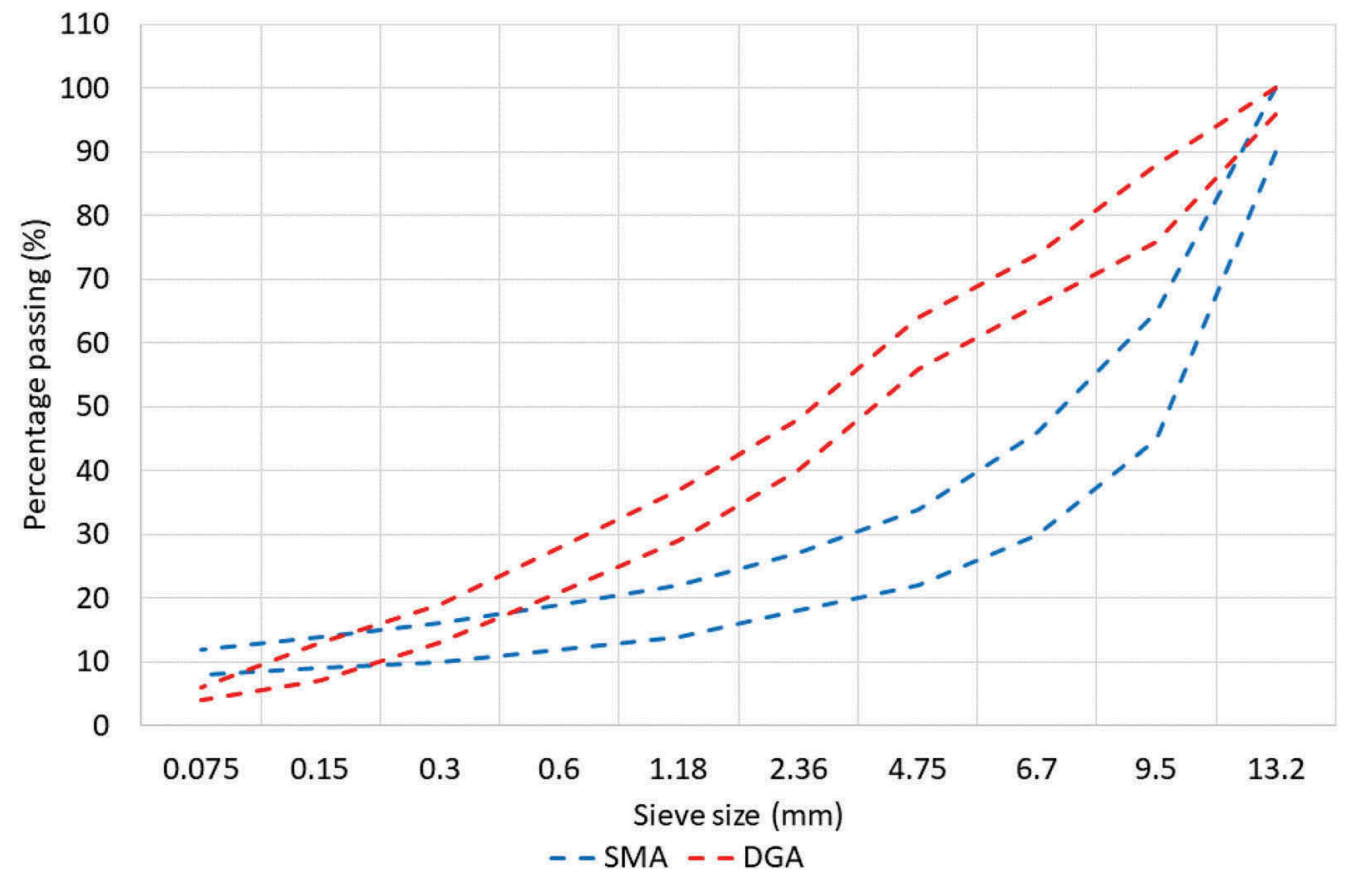

Figure 3. Aggregate grading envelopes for SMA and DGA.

\section{CASE STUDY}

\subsection{Mixture design}

The volumetric composition and performance properties of the $14 \mathrm{~mm}$ sized SMA mixture were designed to meet the requirements of the Australian airport asphalt specification, as shown in Table 4 and Figure 4, which also shows the $14 \mathrm{~mm}$ sized 


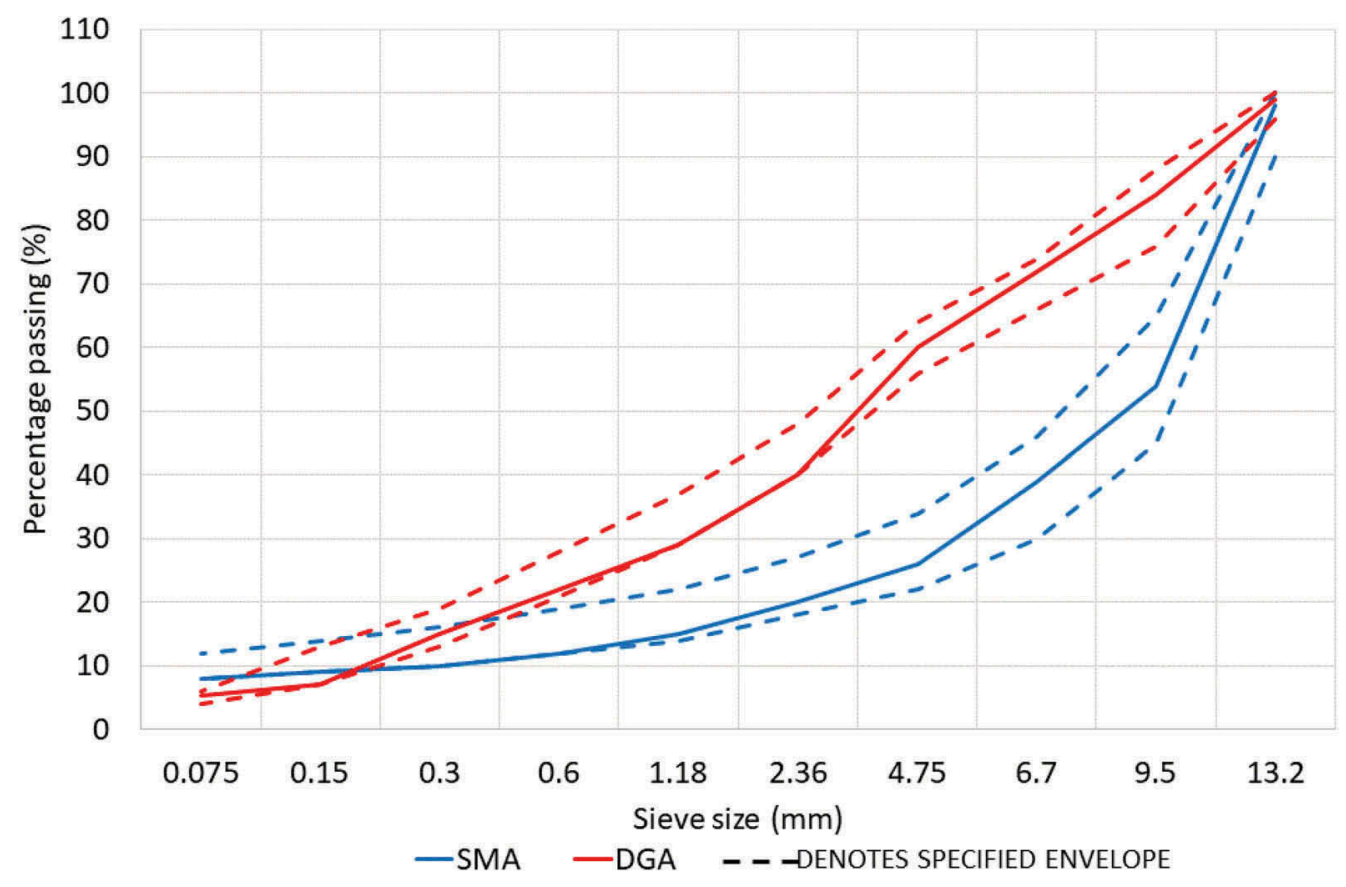

Figure 4. Designed aggregate grading for SMA and DGA.

DGA parameters used for apron/taxiway resurfacing, patching and the runway shape correction layer, as a reference. Both the SMA and DGA mixtures used the same bituminous binder, which was an elastomeric (approximately 7\% SBS) polymer modified binder grade known in Australia as A10E (Austroads 2014). Both mixtures also used the same coarse aggregate and fine aggregate sources. The only exception being the SMA included 3\% crushed lime stone, as well as $1 \%$ hydrated lime. The same hydrated lime was included in the DGA, but the limestone was not included and is not a normal component in airport DGA asphalt mixtures (White 2018). The requirement for crushed lime stone is expensive and logistically complex and is discussed in detail later. Cellulose fibres were added at $0.3 \%$ (by mass) to reduce binder drain down risk.

The SMA and DGA generally showed similar performance in the laboratory, including comparable moisture resistance (TSR), deformation resistance (wheel tracking) and cracking resistance (fatigue life). However, the SMA had a significantly lower resilient modulus and indirect tensile strength, as well as a significantly higher Marshall Flow. These results all reflect the higher binder content associated with the SMA, 6.4\% compared to $5.4 \%$ for DGA. The Marshall Flows were higher than traditionally required for both mixtures, but this reflects the highly elastomeric nature of the A10E binder and a range of $3-5 \mathrm{~mm}$ is normally expected for $14 \mathrm{~mm}$ sized airport DGA produced with A10E.

The mixture design surface texture was measured on the samples of asphalt compacted using a laboratory slab compactor to a target air voids content of $5 \%$, for the Cooper's wheel tracking test. The result was $1.5 \mathrm{~mm}$, which exceeds the $1.0 \mathrm{~mm}$ minimum required by 
Table 4. Designed volumetric and performance properties of SMA and DGA.

\begin{tabular}{lllll}
\hline Property & Units & Test method & SMA & DGA \\
\hline VMA & $\%$ (by volume) & AS/NZS 2891.8 & $18.9(17-20)$ & $14.4(13-17)$ \\
VFB & $\%$ (by volume) & AS/NZS 2891.8 & 78 & 76 \\
Air voids & $\%$ (by volume) & AS/NZS 2891.8 & $3.9(3.0-4.0)$ & $4.2(3.5-4.5)$ \\
Binder content & $\%$ (by mass) & AS/NZS 2891.8 & 6.4 & 5.4 \\
Stability & $\mathrm{kN}$ & AS/NZS 2891.5 & 9.2 & 13.2 \\
Flow & $\mathrm{mm}$ & AS/NZS 2891.5 & 6.2 & 3.7 \\
TSR & $\%$ & AG:PT/T232 & $89(>80)$ & $87(>80)$ \\
Tensile strength & $\mathrm{MPa}$ & AG:PT/T232 & 522 & 1036 \\
Wheel tracking & $\mathrm{mm}$ & AG:PT/T231 & $1.7(<2.0)$ & $1.7(<2.0)$ \\
Fatigue life & $\%$ & AG:PT/T274 & $17(<50)$ & $18(<50)$ \\
Resilient modulus & $\mathrm{MPa}$ & AS/NZ 2891.13.1 & 1,210 & 1,870 \\
\hline
\end{tabular}

regulations for an ungrooved surface. Although surface texture was not measured in the laboratory for the DGA, experience consistently indicates a range of $0.4-0.6 \mathrm{~mm}$ for $14 \mathrm{~mm}$ dense graded airport asphalt (AAA 2017). Furthermore, the binder drain down result was $0.13 \%$, which is below the maximum limit of $0.15 \%$.

Overall, the SMA mixture design achieved the volumetric, performance, surface texture and binder drain down requirements and was approved for use on the runway. Subsequent effort focussed on the construction planning and verifying that the mixture design was achieved in the on-site asphalt production plant.

Values in brackets are specified limits for mixture design purposes, where applicable

\subsection{Construction planning}

Airport specifications in Australia have generally allowed $14 \mathrm{~mm}$ sized DGA to be paved in single layer thicknesses within the range $40-80 \mathrm{~mm}$. The performance-related specification reflects the same requirement for surface layers, but relaxes this for correction layers and patches, to allow works to be performed efficiently in limited night-time work windows (AAPA 2018). Despite this, it is common practice to design and plan construction using a more limited range of layer thicknesses. Consistent with other projects, the Emerald airport minimum designed level lift was $38 \mathrm{~mm}$, providing a minimum DGA planned minimum layer thickness of $45 \mathrm{~mm}$, after $7 \mathrm{~mm}$ deep texturing to remove the existing surface grooves. In contrast, the SMA specification limits the single layer thickness to $45-55 \mathrm{~mm}$ (Jamieson \& White 2019). This reflects the perception that SMA is generally harder to construct without compromising the achieved compaction and surface finish. However, where shape correction is required to optimise the finished surface geometry, the reduced surface layer thickness flexibility reduces the efficiency of the construction.

The Emerald airport runway resurfacing work included significant geometric shape correction, which is typical of all existing airport resurfacing projects, particularly those in regional locations. In addition, the last $300 \mathrm{~m}$ of pavement at each of the runway ends was found to have less structural capacity than the intermediary portion of the runway, so additional asphalt thickness was planned in those areas. Overall, the increase in surface level, from the existing surface to the new surface, was planned to range from $9 \mathrm{~mm}$ to $152 \mathrm{~mm}$, with an average lift of $71 \mathrm{~mm}$. After $7 \mathrm{~mm}$ texturing and deeper profiling to achieve the minimum $45 \mathrm{~mm}$ thickness was taken into account, the new asphalt thicknesses ranged from $45 \mathrm{~mm}$ to $159 \mathrm{~mm}$, with an average of $78 \mathrm{~mm}$. Approximately $50 \%$ of the asphalt thicknesses were between $55 \mathrm{~mm}$ and $80 \mathrm{~mm}$ (Figure 5). 


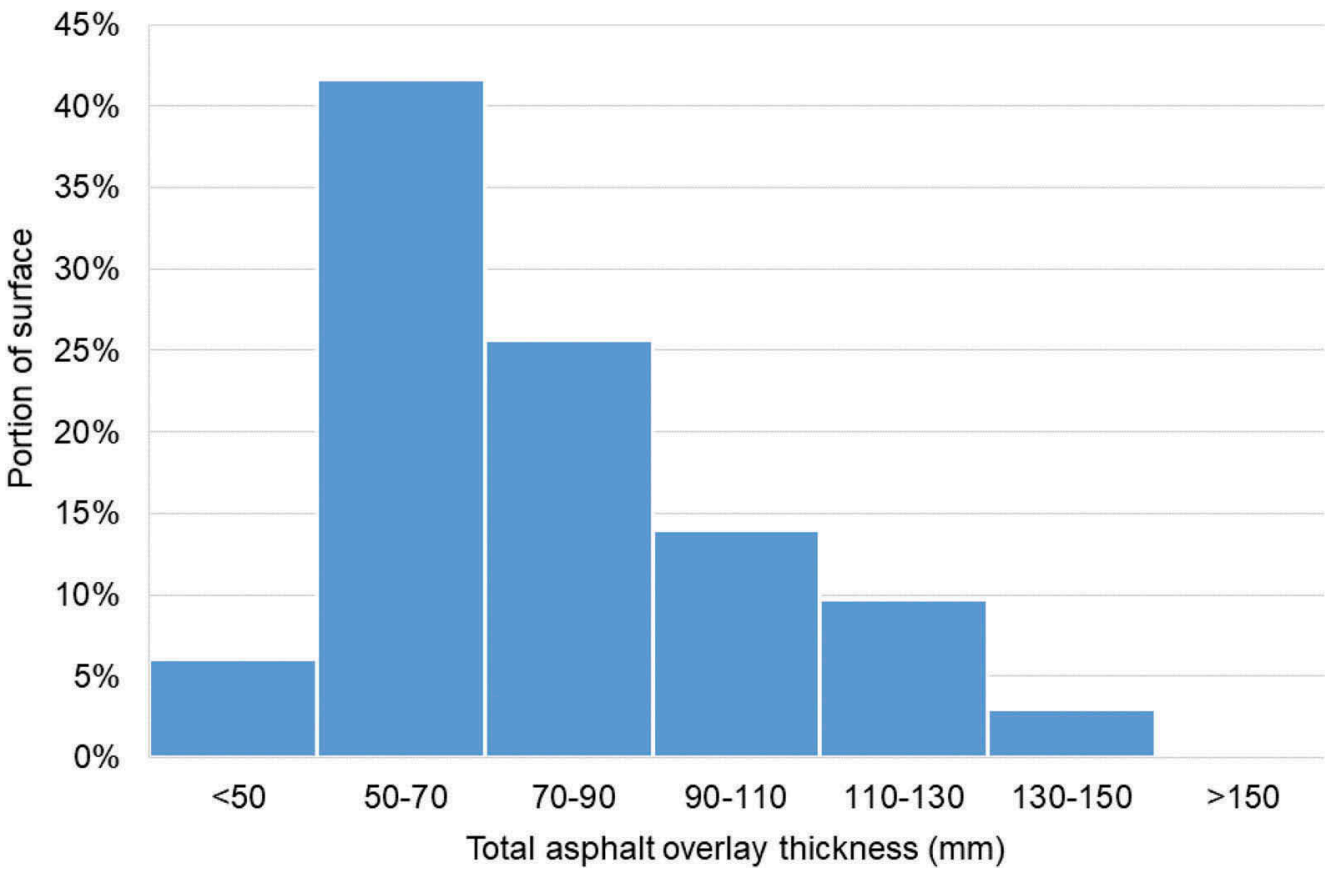

Figure 5. Total (correction and surface) asphalt thickness distribution.

If the job was performed using DGA, the $80 \mathrm{~mm}$ maximum layer thickness would have required $38 \%$ of the runway area to be pre-corrected prior to the $45-80 \mathrm{~mm}$ surface layer being constructed. However, the lower $(55 \mathrm{~mm})$ maximum layer thickness for SMA meant that $86 \%$ of the runway required correction prior to surfacing with $45-55 \mathrm{~mm}$ thick SMA. Furthermore, the distribution of correction thickness changed from a relatively uniform spread from $5 \mathrm{~mm}$ to $55 \mathrm{~mm}$ for the DGA option (Figure 6) to being dominated by thinner $5 \mathrm{~mm}$ to $25 \mathrm{~mm}$ of correction for the $45-55 \mathrm{~mm}$ SMA option (Figure 6). This issue was further exacerbated when the minimum thickness of $14 \mathrm{~mm}$ sized DGA, as a correction layer $(30 \mathrm{~mm})$ was taken into account. Significantly deeper profiling would be required to achieve a minimum $30 \mathrm{~mm}$ thickness of DGA correction layer, even where the target correction lift was only $5-25 \mathrm{~mm}$.

As detailed below, the construction trial included SMA thicknesses from $40 \mathrm{~mm}$ to $65 \mathrm{~mm}$. Based on the positive results, the SMA thickness limits were revised to 45-65 mm. This reduced the area of the runway requiring correction from $86 \%$ to $62 \%$ of the total runway area. However, the correction thickness was still dominated by $5 \mathrm{~mm}$ to $15 \mathrm{~mm}$ lifts (Figure 6) meaning that significant profiling was still required. To further reduce this requirement, a $10 \mathrm{~mm}$ sized DGA mixture was designed. The $10 \mathrm{~mm}$ sized DGA was allowed to be constructed in layers $20-40 \mathrm{~mm}$ thick, reducing the profiling and associated correction layer volume of asphalt significantly.

It is noted that the alternate approaches to minimising the correction layer area and thickness were also considered. These included constructing all the DGA first and then the SMA. However, this would leave unacceptable steps in the runway between work periods and this option was not viable. Feathering out the correction layer to effectively zero thickness was also considered. This approach is generally only permitted on runways where the surface layer is constructed over the correction layer in the same work period, so that aircraft never traffic 


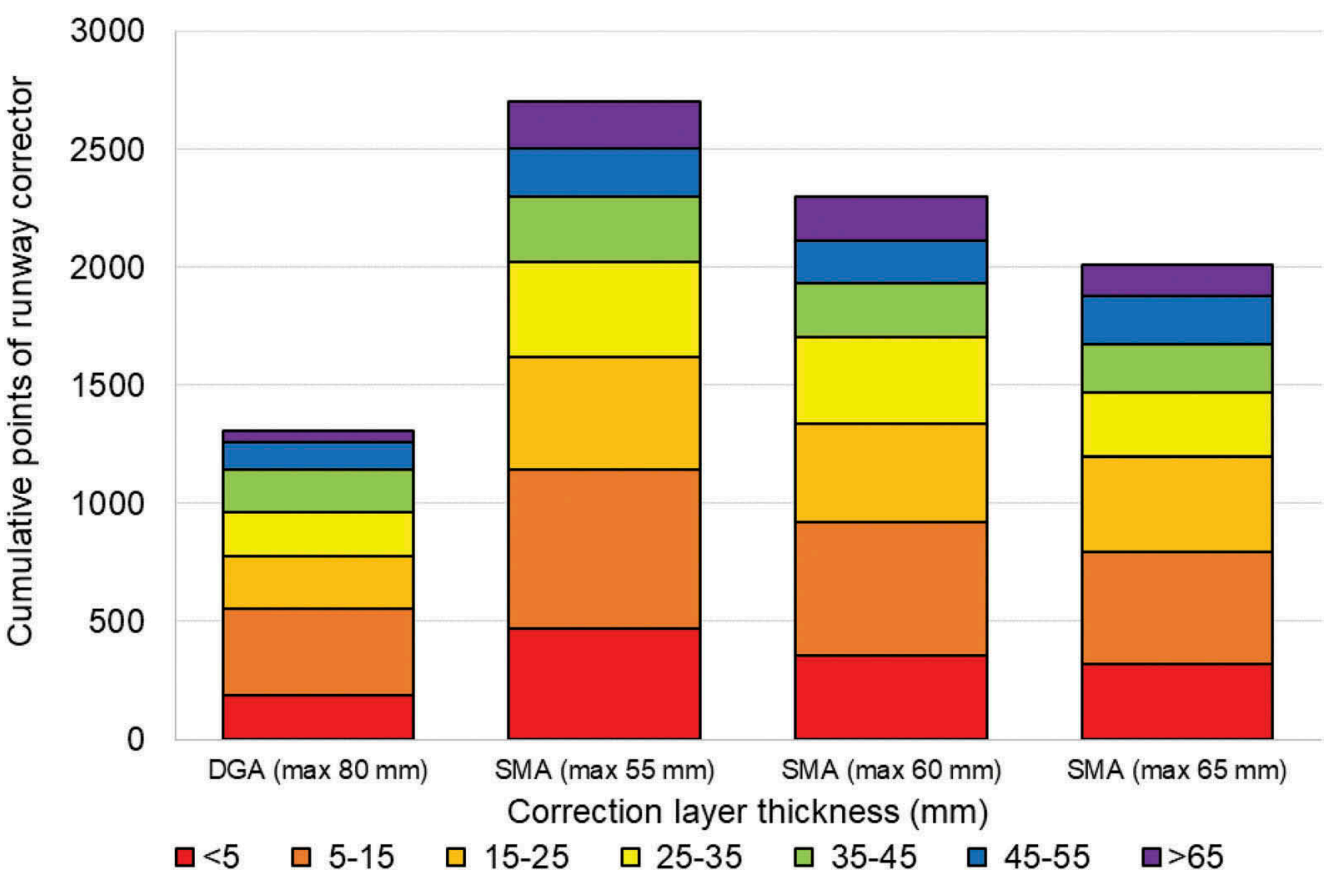

Figure 6. Correction layer thickness distribution for various surface layer thicknesses.

the feathered edge of the corrector, which would introduce the risk of loose stones ravelling out and damaging aircraft engines and undercarriage. Consequently, this approach was only viable if the SMA surface layer was constructed in the same work period as the DGA correction layer. However, the time required to change aggregate storage bins and clean out the plant and equipment, to avoid contamination of the SMA with residual DGA, was considered prohibitive and this option was abandoned at the contractor's discretion, despite it being technically feasible.

The effect of the reduced layer thickness range associated with SMA surfaces was the single biggest issue encountered on the Emerald airport runway overlay. In part, this was a function of the required surface level lifts and associated shape correction. However, the challenge associated with SMA as an ungrooved runway surface, where shape correction is required, was highlighted. Consequently, it was concluded that SMA is more viable where either two layers of asphalt surface are proposed over the full runway length and width, allowing all correction to be performed in the lower (DGA) layer, or where surface correction requirements are minimal, so that the correction can be performed within the thickness limits of a single SMA layer.

\subsection{Construction trial}

As shown in Figure 1 the construction trial was located on the secondary runway. This allowed wetted friction testing to be performed prior to the surface SMA layer construction commencing. The friction testing results are detailed later. The construction trial included a $100 \mathrm{~m}$ long section of DGA as well as a $100 \mathrm{~m}$ long section of SMA. Both sections were two paver runs wide, totaling $7.5 \mathrm{~m}$.

In addition to the normal construction verification processes, the construction trial allowed a relaxation of the SMA thickness to be tested. The SMA trial was nominally 40-65 mm thick. There was no difference in the surface texture, visual appearance, air voids, level control or 
joint condition noticed throughout the variable thickness SMA trial section. Consequently, the SMA single layer thickness limits were relaxed from $45-55 \mathrm{~mm}$ to $45-65 \mathrm{~mm}$, significantly reducing the area of correction layer required and the volume of existing surface profiling required to accommodate the minimum correction later thickness. The trial also allowed the nuclear density gauge to be calibrated to both the DGA and SMA mixtures, which is critical when non-destructive (gauge-based) density testing is adopted for construction acceptance (White \& Alrashidi 2021).

Apart from the normal production and construction compliance verification, the primary function of the construction trial was to allow the owners of the airport to inspect, evaluate and otherwise test the SMA surface in a less critical area of the airfield, before it was confirmed for the main runway surfacing. The correction layer construction and the apron/taxiway work allowed a period of four weeks between construction of the trial sections and commencement of the main runway SMA surface layer construction. During this period the trial area was visually assessed, coarse aggregate was attempted to be mechanically dislodged, the volumetric macro-texture was measured and an ICAOapproved self-wetting CFME survey was performed one day and seventeen days after the SMA trial was constructed.

All production and construction compliance requirements were achieved, the surface was found to be consistent and the coarse aggregate could not be mechanically dislodged. The wetted friction values exceeded the ICAO maintenance intervention values required at both $65 \mathrm{~km} / \mathrm{hr}$ and $95 \mathrm{~km} / \mathrm{hr}$ test speeds (Figure 7) and the surface macrotexture exceeded the regulatory minimum average $1 \mathrm{~mm}$ (Table 5). The DGA trial results are included for reference. The average friction values reduced slightly from day 1 to day 17, which reflected the reduced tackiness of the surface immediately after construction. The surface texture results were generally lower than the $1.5 \mathrm{~mm}$ reported during the mixture design, but were acceptable.

Overall, the construction trial was a success, confirming all production and construction processes and validating the SMA surface macro-texture and wetted friction values met the regulatory requirements for an ungrooved runway surface. The trial provided a sound benchmark for the asphalt production and surface construction on the main runway.

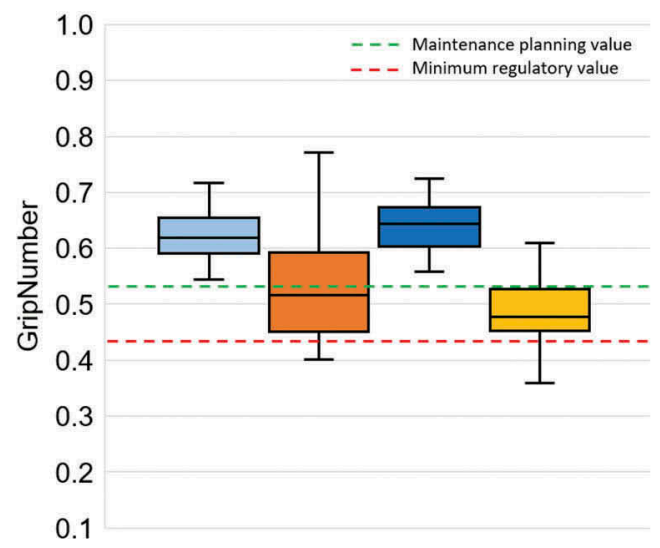

口Day 1 SMA 口Day 1 DGA $\square$ Day 17 SMA $\square$ Day 17 DGA

(a) $65 \mathrm{~km} / \mathrm{hr}$ test speed

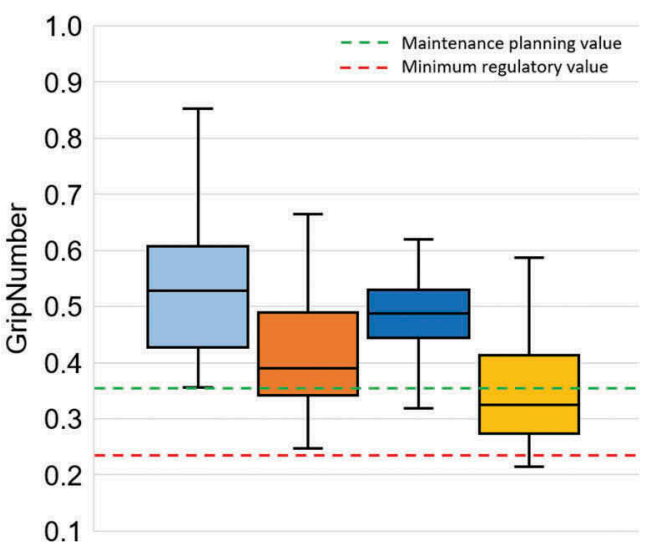

口Day 1 SMA IDay 1 DGA घDay 17 SMA ロDay 17 DGA

(b) $95 \mathrm{~km} / \mathrm{hr}$ test speed

Figure 7. Wetted surface friction results of construction trial SMA and DGA. 
Table 5. Statistics of construction trial SMA macro-texture.

\begin{tabular}{lcc}
\hline Statistics & SMA value $(\mathrm{mm})$ & DGA value $(\mathrm{mm})$ \\
\hline Minimum & 0.94 & 0.46 \\
Average & 1.10 & 0.51 \\
Maximum & 1.23 & 0.62 \\
Count of results & 10 & 10 \\
\hline
\end{tabular}

\subsection{Asphalt production}

One of the concerns expressed by practitioners is the ability of continuous drum mixing plants, which dominate in Australia, to consistently achieve the tight asphalt production requirements normally associated with airport surfacing. Although the asphalt production tolerances are usually achieved for DGA, the majority of SMA aggregate is provided by the $14 \mathrm{~mm}$ aggregate fraction, meaning that the produced asphalt grading is highly reliant on the consistency of the $14 \mathrm{~mm}$ aggregate fraction grading. Despite this concern, the currently specified asphalt production tolerances for SMA are no different to those for DGA.

The asphalt production results were compared to the specified asphalt production tolerances (Table 6). The magnitude of a 95\% confidence interval was also calculated based on the production data. All of the aggregate grading $95 \%$ confidence internals were smaller than the tolerance width, meaning that $95 \%$ of the results were within the specified tolerance. The only SMA production properties with a 95\% confidence interval larger than the production tolerance were the binder content, as well as the mathematically linked air void content. However, this was not the result of SMA production. Unlike the aggregate grading, which is fundamentally different for SMA, binder addition and mixing is identical for both mixture types. Rather than being a production issue, the higher variability associated with binder content is a testing issue. The higher fines and binder content required for SMA means that the tools used in the on-site laboratory become covered in excess mastic. The tools must be manually cleaned and the mastic manually split and added to the four sub-samples of loose asphalt that are used for the various production quality assurance tests. This unavoidably affects the subsequently measured binder content. Consequently, a larger production tolerance for binder content may be justified for SMA, compared to DGA, primarily to reflect this challenge associated with the sampling, splitting and testing of SMA. Because the air voids are calculated for the same samples as the binder content is tested, the variable binder content also affects the air voids results.

\subsection{Surface construction}

The SMA was monitored during the works and has been inspected periodically since its completion. Based on feedback from the paving crew managers and the visual inspections, generally the SMA:

- was no more difficult to pave, compact and finish than the DGA produced as part of the same project,

- produced a tight and generally consistent surface finish with the expected surface texture (Figure 8),

- had tight and almost undetectable hot construction joints between paving lanes, and

- had well matched and finished cold construction joints between work periods. 
Table 6. Asphalt production variability compared to tolerances.

\begin{tabular}{lclccc}
\hline Property & Average & Std. Dev. & CoV & $95 \%$ CI & Tolerance \\
\hline VMA (\%) & 19.2 & 0.4 & $2.0 \%$ & 1.6 & 4.0 \\
Air voids (\%) & 3.8 & 0.8 & $21.9 \%$ & $\mathbf{3 . 2}$ & 3.0 \\
Binder content (\%) & 6.4 & 0.3 & $4.3 \%$ & $\mathbf{1 . 2}$ & 0.6 \\
Stability (kN) & 8.9 & 0.9 & $10.6 \%$ & 3.6 & 6.0 \\
Flow (mm) & 6.3 & 0.5 & $8.6 \%$ & 1.8 & 2.0 \\
Percentage passing (\%) & the sieve sized (mm) & & & & \\
13.2 & 93 & 2.2 & $2.3 \%$ & 9 & 12 \\
9.5 & 61 & 2.4 & $3.9 \%$ & 10 & 12 \\
6.7 & 37 & 2.5 & $6.7 \%$ & 10 & 12 \\
4.75 & 30 & 2.3 & $7.5 \%$ & 9 & 12 \\
2.36 & 21 & 1.4 & $6.9 \%$ & 6 & 10 \\
1.18 & 15 & 1.1 & $7.3 \%$ & 4 & 10 \\
0.6 & 12 & 0.9 & $7.4 \%$ & 4 & 8 \\
0.3 & 9.9 & 0.8 & $7.7 \%$ & 3.2 & 6 \\
0.1 & 8.4 & 0.7 & $8.0 \%$ & 2.8 & 4.0 \\
0.075 & 6.8 & 0.6 & $8.1 \%$ & 2.4 & 3.0 \\
\hline
\end{tabular}

$\mathrm{VMA}=$ voids in the mineral aggregate. Std. Dev. is the standard deviation. CoV is the coefficient of variability. $95 \% \mathrm{CI}$ is equal to four times the Std. Dev. and represents the range of values, centred on the average, expected to included $95.4 \%$ of the results. Tolerance is two times the specified tolerance, which is specified as a \pm value deviation from the target. Values in red identify where the $95 \%$ CI was not smaller than the tolerance.

The only blemish associated with the SMA was three isolated bitumen-rich spots, such as the example in Figure 9. These small areas were all located within the first paving run of the respective work periods, meaning they were associated with the first SMA produced that evening. The SMA had been stored in the truck too long and some of the binder had drained down to the bottom to become a localised area of excessive binder that subsequently bled to the surface during rolling and created the bitumen-rich spot. This was subsequently minimised by reducing the time between the first SMA production and the commencement of paving. The three areas totalled $4 \mathrm{~m}^{2}$ $(<0.01 \%$ of the runway surface area) and although the surface texture was reduced to below the regulatory $1 \mathrm{~mm}$ minimum, the air voids remained within the specified limits and the three isolated areas were deemed to be of no practical importance.

The primary properties tested for surface construction are the in-field air voids content and surface texture, with the wetted friction measured on completion of the physical work. The surface texture and wetted friction are discussed below. The in-field air voids content results all met the specified limits, both on the joints and away from the joints, based on both individual results and the average value for each work period (Table 7) with just one exception. One individual result (out of 165) away from the joints fell below the $2 \%$ minimum, at $1.5 \%$. This one-off was considered an anomaly.

Overall, the surface construction met all expectations with the only exception being the minor and isolated bitumen-rich areas, commonly known as fatty spots, which were subsequently avoided by ensuring that the asphalt was produced and paved in a timeframe that prevented the binder draining to the bottom of the cartage trucks prior to the commencement of paving each work period.

\subsection{Aircraft skid resistance}

Despite the positive results from the construction trial, aircraft skid resistance was continually monitored through the construction by volumetric surface macro-texture testing and was 


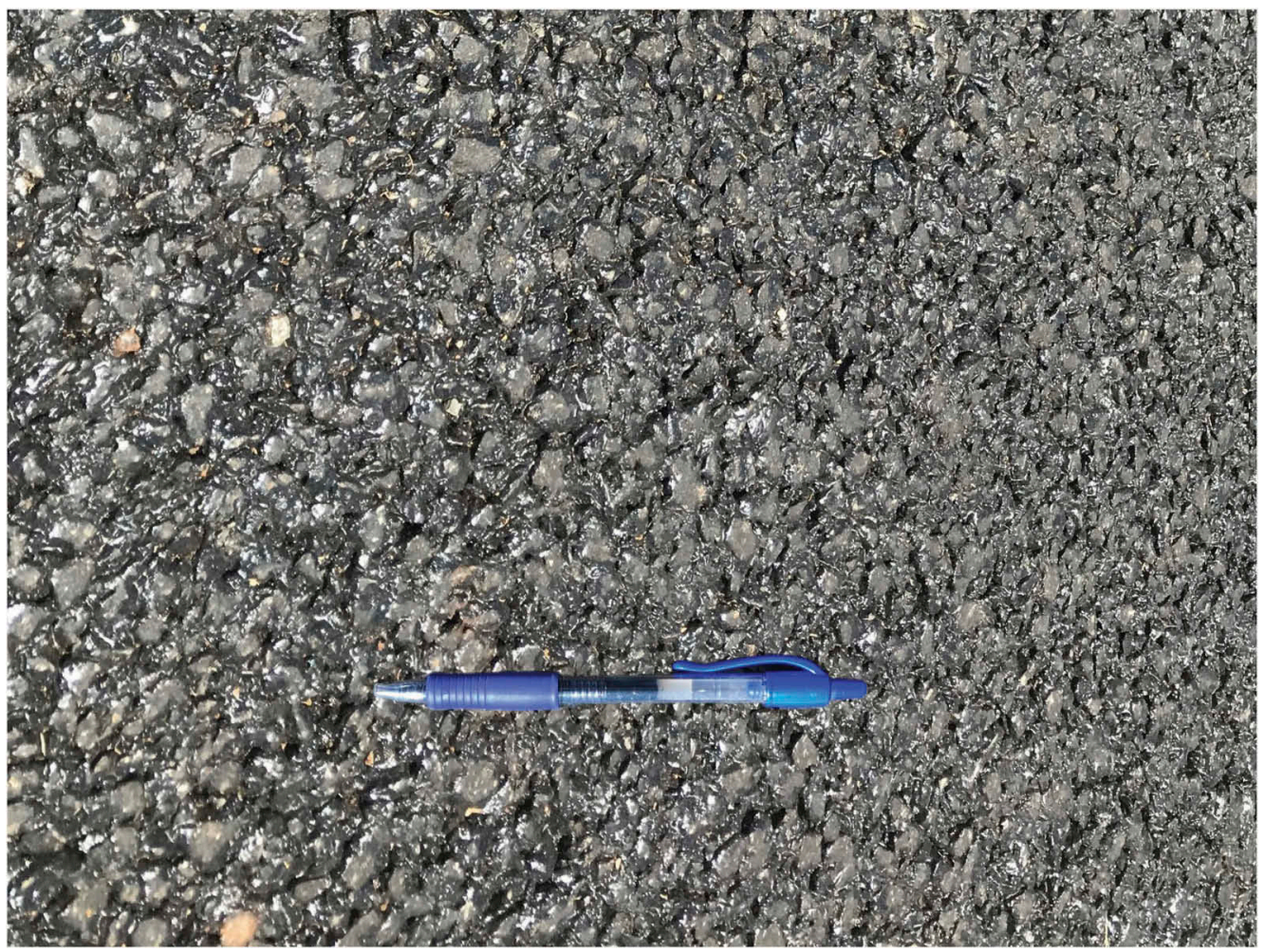

Figure 8. Typical SMA surface finish.

verified on completion by wetted friction testing using the same CFME used on the construction trial area.

The surface texture results ranged from $1.0 \mathrm{~mm}$ to $1.7 \mathrm{~mm}$, with an average of $1.3 \mathrm{~mm}$ (Figure 10). This was consistent with the construction trial area and reliably exceeded the $1.0 \mathrm{~mm}$ minimum value, without exceeding this regulatory requirement excessively.

The runway friction testing results were averaged over $100 \mathrm{~m}$ lengths of the runway, which is normal practice for runway friction surveys. Because runways are tested at four offsets and two directions, each $100 \mathrm{~m}$ section is actually tested eight times. The combined eight $100 \mathrm{~m}$ run result values are shown in Figure $11(65 \mathrm{~km} / \mathrm{hr})$ and Figure $12(95 \mathrm{~km} / \mathrm{hr})$. It was noted that the $100 \mathrm{~m}$ section at each end of the runway had higher variability and significantly higher friction values, at both test speeds, compared to the rest of the runway length. This reflects the unreliability of the results as the test device was accelerated to the target speed and these results are generally excluded from any compliance evaluation. Even excluding the $100 \mathrm{~m}$ at each runway end, the results all exceeded the regulatory minimum and maintenance intervention levels (Table 8) meaning that the runway was immediately compliant with regulatory aircraft skid resistance requirements, within a week of resurfacing. This contrasts with grooved DGA, which generally requires grooving to achieve compliance, with the grooving processes commonly delayed until 4-8 weeks after resurfacing, to allow the asphalt to cure as the initial volatiles are lost (AAA 2017).

Some practitioners have expressed concern that the high level of surface texture will allow water to enter the mix and cause moisture damage. The mixture design testing (Table 4) indicated a high resistance to moisture damage, with a TSR of $89 \%$, compared 


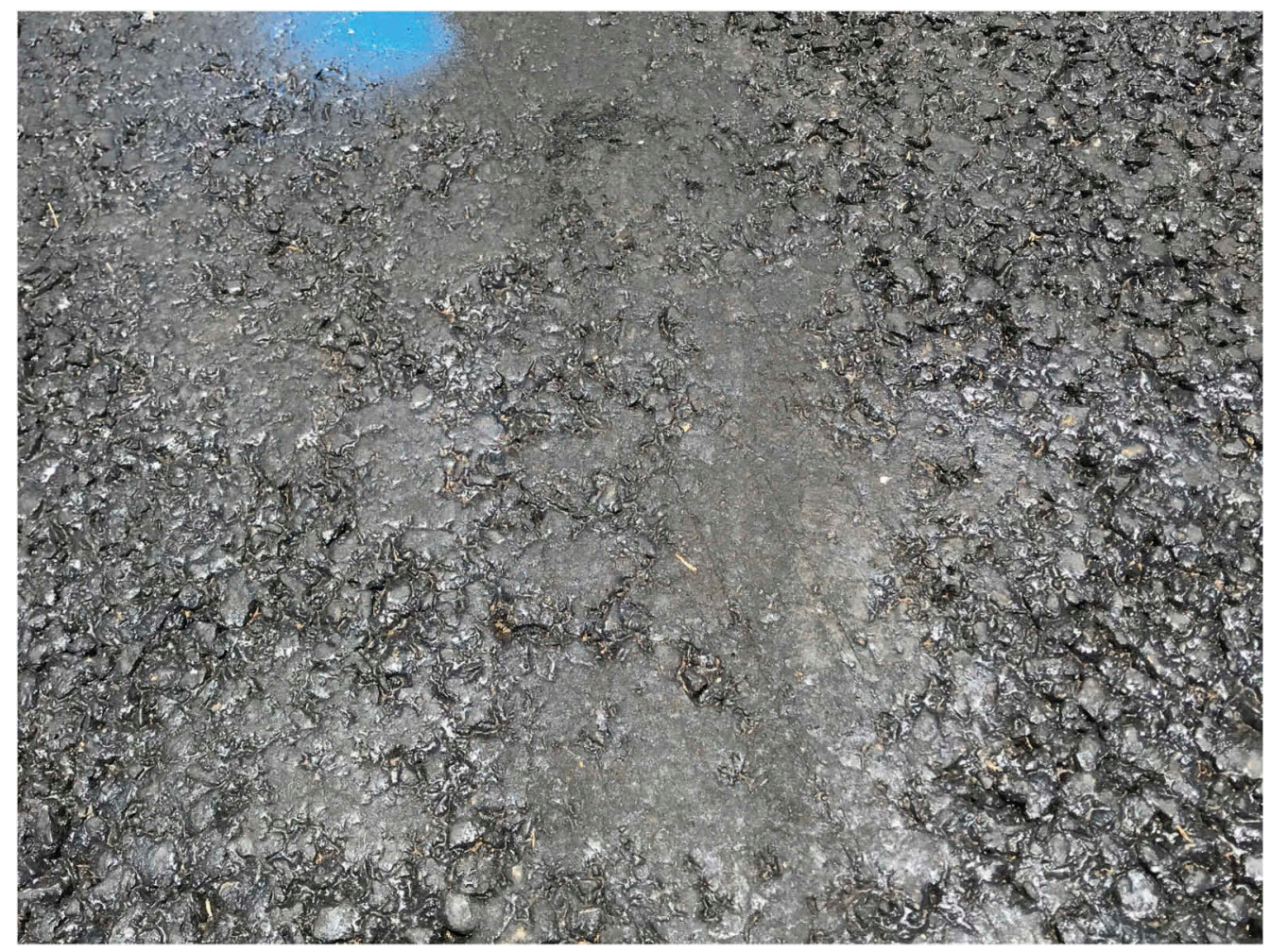

Figure 9. Example of isolated bitumen-rich area of SMA.

Table $7 . \quad$ In-field air voids content $(\%)$ results.

\begin{tabular}{lcccc}
\hline & \multicolumn{3}{c}{ Away from joints } & \multicolumn{3}{c}{ On the joints } \\
\cline { 2 - 5 } Statistic & Individual & Average & Individual & Average \\
\hline Minimum & 1.5 & 2.7 & 2.5 & 4.8 \\
Average & 3.9 & 3.9 & 5.6 & 5.6 \\
Maximum & 5.7 & 4.5 & 8.2 & 6.5 \\
Std. Dev. & 0.97 & 0.49 & 1.37 & 0.66 \\
Count of results & 165 & 17 & 64 & $3.0-8.0$ \\
Specified limits & $2.0-6.0$ & $3.0-5.0$ & $2.0-9.0$ & \\
\hline
\end{tabular}

to the DGA mixture results of $87 \%$. However, to demonstrate the impermeable nature of the SMA, bulk material was sampled during SMA production and was tested for permeability using a falling head test on samples prepared in a gyratory compactor with different target air void contents. The results showed that the SMA was impermeable at air void contents below approximately 7\% (Figure 13). Because the field air void contents ranged from $1.5 \%$ to $5.7 \%$, the surface was considered impermeable, except at the 


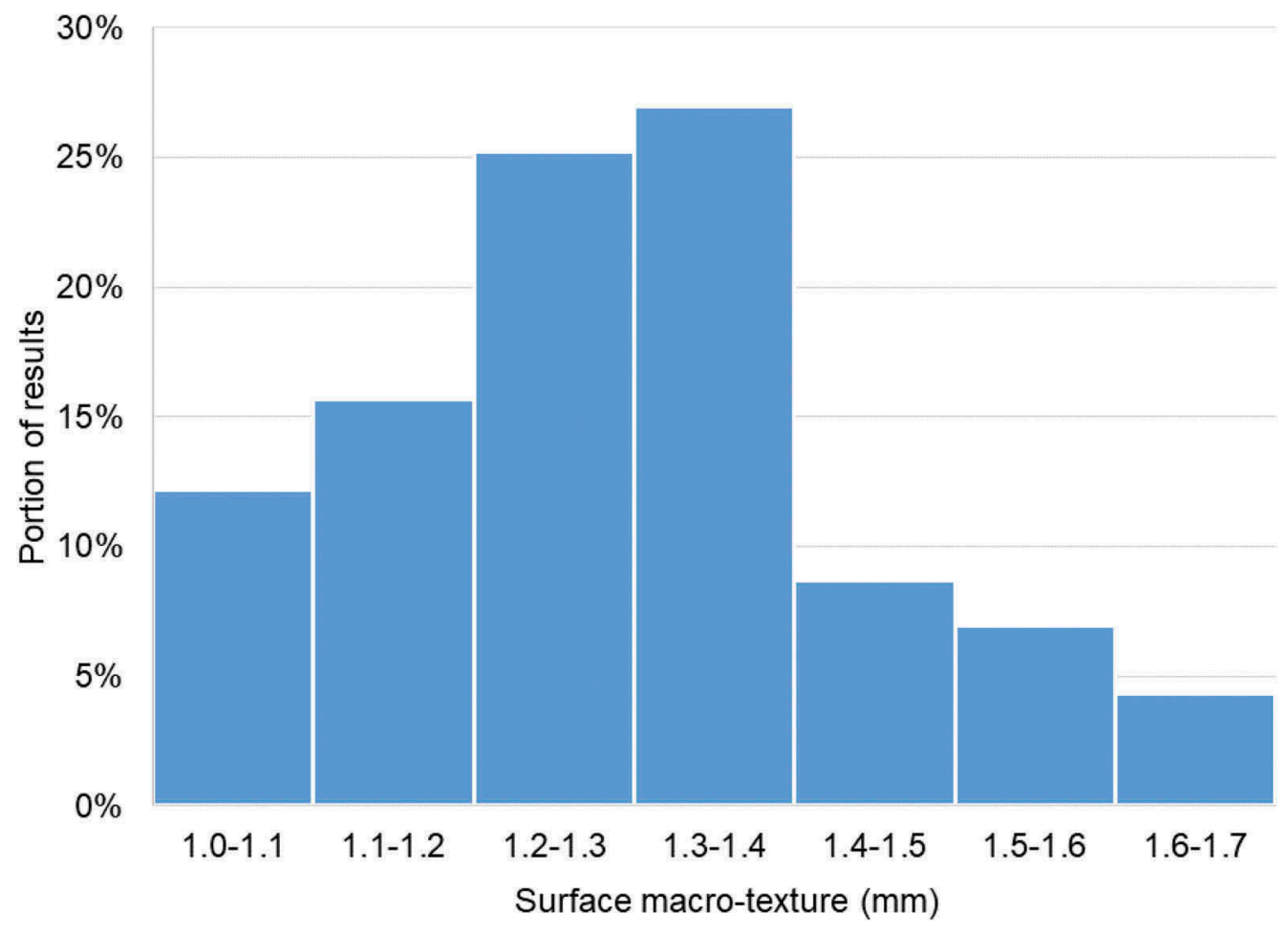

Figure 10. Distribution of SMA surface macro-texture results.

joints. That is, despite the high surface texture, the SMA does not allow water to drain through interconnected air voids and the SMA is consequently no more susceptible to moisture damage that DGA.

\subsection{Cost comparison}

To allow Emerald airport to consider their options, both grooved DGA and ungrooved SMA options were tendered. The tendered costs were $\$ 8.9 \mathrm{M}$ (grooved DGA) and $\$ 9.5$ M (ungrooved SMA). The difference reflects the omission of grooving but the higher cost of SMA associated with the higher binder content, the inclusion of fibres to reduce binder drain down and the reduced productivity associated with the increased area required to be corrected prior to constructing the surface layer. In contrast to the additional cost associated with the SMA option, SMA is well established as having a greater expected service life, evidenced by research from the USA (Yin \& West 2018) and experience at Cairns airport (Jamieson \& White 2020). Based on an expected four year longer service life associated with the SMA, the ungrooved SMA has an annualised depreciation rate that is $25 \%$ lower than grooved DGA (Table 9). It is also shown that even if the ungrooved SMA service life is only one year longer than for the grooved DGA, the annualised depreciation is still lower for ungrooved SMA than for grooved DGA. The Emerald airport runway surface must be monitored over its lifecycle and its condition compared to the adjacent DGA to determine the actual increase in surface life. 


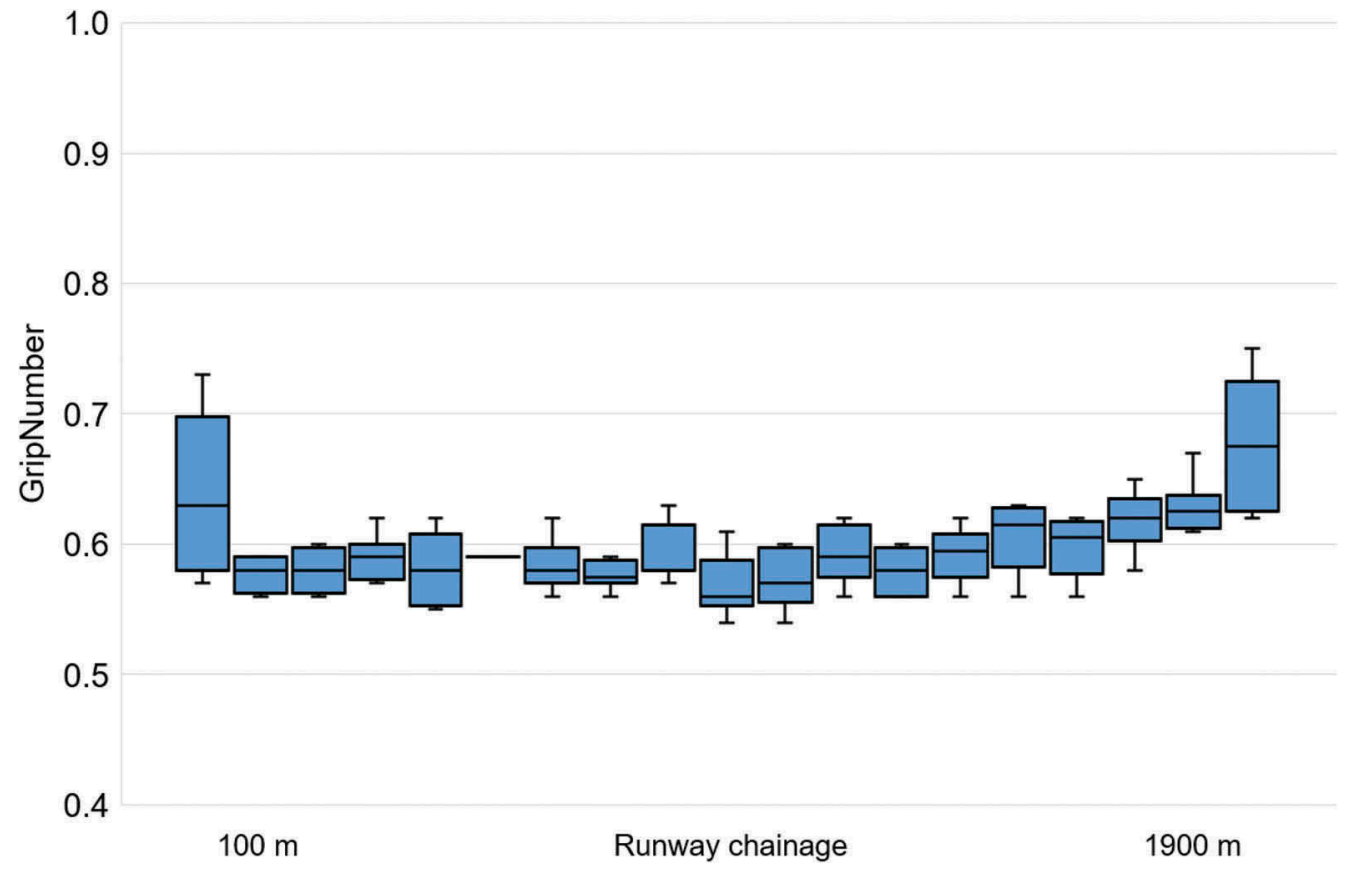

Figure 11. $65 \mathrm{~km} / \mathrm{hr}$ SMA wetted friction values.

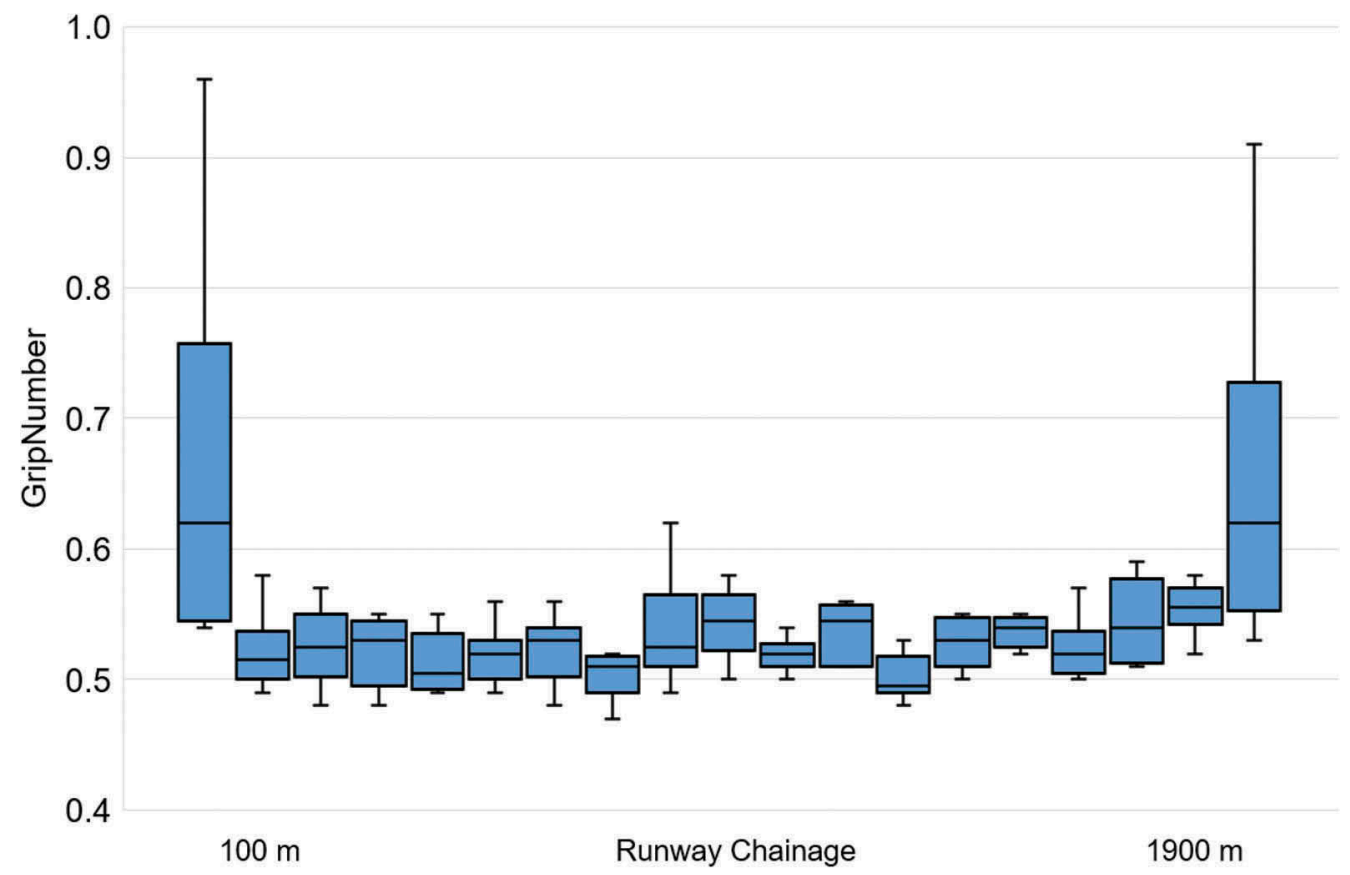

Figure 12. $95 \mathrm{~km} / \mathrm{hr}$ SMA wetted friction values. 
Table 8. Runway CFMD friction levels six days after resurfacing.

\begin{tabular}{lllll}
\hline & \multicolumn{2}{l}{$65 \mathrm{~km} / \mathrm{hr}$ test speed } & \multicolumn{2}{l}{$95 \mathrm{~km} / \mathrm{hr}$ test speed } \\
\cline { 2 - 5 } Statistic & Full length & $\begin{array}{l}\text { Excluding } \\
\text { ends }\end{array}$ & Full length & $\begin{array}{l}\text { Excluding } \\
\text { ends }\end{array}$ \\
\hline Minimum & 0.54 & 0.54 & 0.47 & 0.47 \\
Average & 0.60 & 0.58 & 0.54 & 0.53 \\
Maximum & 0.75 & 0.67 & 0.96 & 0.62 \\
Std. Dev. & 0.04 & 0.02 & 0.06 & 0.03 \\
Count of results & 152 & 136 & 152 & 136 \\
Regulatory minimum & 0.43 & & 0.24 & \\
Maintenance & & & & 0.36 \\
intervention & 0.53 & &
\end{tabular}

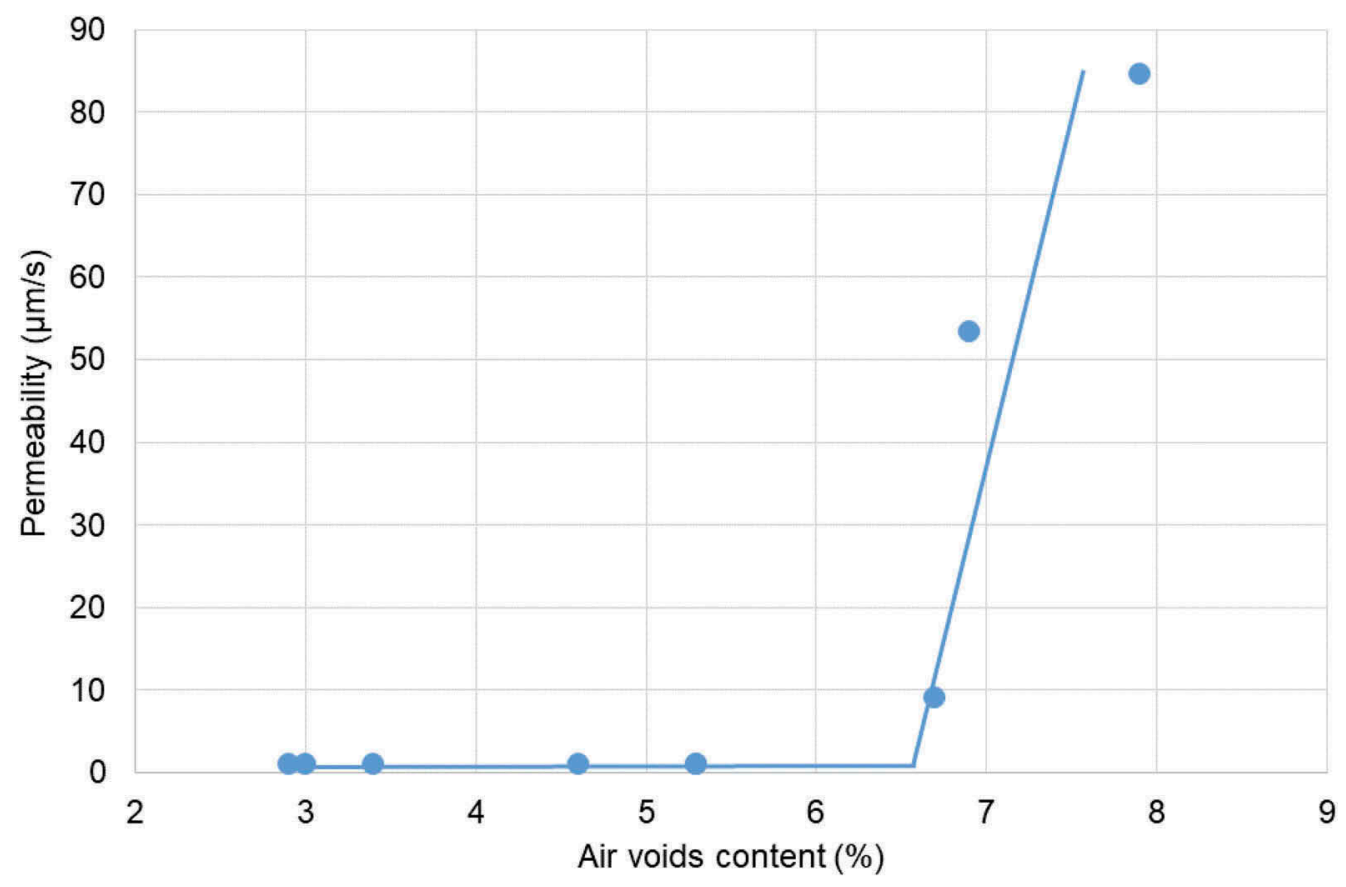

Figure 13. SMA permeability increase with air voids content.

Table 9. Annualised surface depreciation for different service lives.

\begin{tabular}{llll}
\hline Service life & Ungrooved SMA & Grooved DGA & SMA to ten year DGA \\
\hline 10 years & $\$ 0.93 \mathrm{k} /$ annum & $\$ 0.89 \mathrm{k} / \mathrm{annum}$ & $104 \%$ \\
11 years & $\$ 0.85 \mathrm{k} /$ annum & - & $95 \%$ \\
12 years & $\$ 0.78 \mathrm{k} /$ annum & - & $87 \%$ \\
13 years & $\$ 0.72 \mathrm{k} /$ annum & - & $80 \%$ \\
14 years & $\$ 0.68 \mathrm{k} /$ annum & - & $75 \%$ \\
15 years & $\$ 0.68 \mathrm{k} /$ annum & - & $70 \%$ \\
\hline
\end{tabular}




\section{CONCLUSIONS}

The pilot project at Emerald airport has achieved the aim of demonstrating ungrooved SMA as a viable alternate to grooved DGA for runway surfacing. The mixture designs indicated that the SMA is expected to perform in the field similarly to DGA, with regard to fracture, deformation and moisture damage resistance. The construction trial confirmed that the surface texture exceeded the regulatory requirements, as did the wetted surface friction values. Furthermore, the aircraft skid resistance compliance was achieved immediately following construction, which is a significant advantage over grooved DGA, which usually does not achieve compliance until the grooves are sawn some 4-8 weeks later. The production and construction results similarly confirmed the aircraft skid resistance requirements were met, as well as the ability of the continuous drum mixing plant to achieve adequate SMA production consistence, comparable to that expected for DGA. However, it is recommended that the asphalt production binder content acceptance tolerance be increased for SMA, to reflect the more variable nature of the test resulting from unavoidable contamination of the tools by the high bituminous binder content. The Emerald airport project also highlighted the need to monitor the SMA construction to minimise the risk of isolated bitumen-rich spots. Overall, the project was considered a successful pilot and it is recommended that other airports consider ungrooved SMA as an alternate to grooved DGA in the future. Ongoing monitoring of the Emerald Airport SMA surface is required to determine the performance with age, compared to the otherwise similar DGA in the same environment.

\section{REFERENCES}

AAA 2017, Airfield Pavement Essential, Airport Practice Note 12, Australian Airports Association, Canberra, Australian Capital Territory, Australia, April.

AAPA 2018, Performance-based Airport Asphalt Model Specification, Australian Asphalt Pavement Association, Melbourne, Victoria, Australia, ver. 1.0, January.

Austroads 2014, Specification Framework for Polymer Modified Binders, Report AGPT/T190, Austroads, February.

CASA 2019, Manual of Standards: Part 139 - Aerodromes, Civil Aviation Safety Authority, Canberra, Australian Capital Territory, Australia, 5 September.

FAA 1997, Measurement Construction and Maintenance of Skid-Resistant Airport Pavement Surfaces, Advisory Circular 150/5320-12C, Federal Aviation Administration of the United States of America.

ICAO 2013, Aerodrome Design and Operations. Annex 14, Volume 1, to the Conventions on International Civil Aviation, International Civil Aviation Organization, Montreal, Canada, February.

Jamieson, S 2019, Stone Mastic Asphalt for Australian Airport Asphalt, A thesis submitted for the award of Master of Science in Civil Engineering, University of the Sunshine Coast, Sippy Downs, Queensland, Australia, 17 June.

Jamieson, S \& White, G 2020, 'Review of stone mastic asphalt as a high performance ungrooved runway surfacing', Road Materials and Pavement Design, vol. 21, no. 4, pp. 886-905.

Jamieson, S \& White, G 2019, 'Developing a performance-based specification for stone mastic asphalt as an ungrooved runway surface', International Airfield and Highway Pavements Conference, Chicago, Illinois, USA, 21-24 July.

White, G 2018, 'State of the Art: Asphalt for Airport Pavement Surfacing', International Journal of Pavement Research and Technology, vol. 11, no. 1, pp. 77-98.

White, G \& Alrashidi, F 2021, 'Field evaluations of nuclear and non-nuclear gauges as alternates to destructive coring for airport asphalt density testing', International Symposium on Frontiers of Road and Airport Engineering, Delft, Netherlands, 12-14 July.

White, G \& Azevedo, R 2022, 'Managing the evolution of early-life runway surface friction', $11^{\text {th }}$ International Conference on Managing Pavement Assets, Chicago, Illinois, USA, 7-10 June, article-in-press.

White, G, Ward, C \& Jamieson, S 2019, 'Field evaluation of a handheld laser meter for pavement surface macro texture measurement', International Journal of Pavement Engineering, article-in-press, doi.org/ $10.1080 / 10298436.2019 .1654103$. 
White, TD 1985, 'Marshall procedures for design and quality control of asphalt mixture', Proceedings Asphalt Pavement Technology, no. 54, pp. 265-285.

Yin, F \& West, R 2018, 'Performance and life-cycle cost benefits of stone matrix asphalt', $1^{\text {st }}$ International Conference on Stone Matrix Asphalt, Atlanta, Georgia, USA, 5-7 November.

Zuzelo 2014, 'The Benefits of Runway Grooving', Presented to the Airfield Engineering and Maintenance Summit, Furama Riverfront, Singapore, 25-28 March.

Central Highlands Regional Council gave permission for the publication of this paper and Boral Asphalt supported its preparation. These critical contributions by the asset owner and the contractor are greatly appreciated and gratefully acknowledged. 